\title{
Pulmonary Sulcus Neoplasm
}

National Cancer Institute

\section{Source}

National Cancer Institute. Pulmonary Sulcus Neoplasm. NCI Thesaurus. Code C27710.

A neoplasm originating from the apical lung. Most superior sulcus neoplasms are

bronchogenic carcinomas. This tumor may be associated with Pancoast syndrome. It is also known as Pancoast tumor. 